HOW TEACHERS OF PHYSICS ARE "MADE IN GERMANY."

\author{
By E. A. Strong, \\ Ypsilanti, Michigan.
}

In the September number of Zeitschrift fuer den Physikalischen und Chemischen Unterricht Professor E. Wiedemann of Erlangen gives, at the request of the management of that journal, his notion of the best university preparation for teachers of physics in the middle schools-gymnasia, real schools, etc. Those who wish to know about the preparation of teachers for the public schools (primary schools), and especially how the law of I90I affected this matter, will find an admirable French view of the whole subject now running in Rerue Pedagogique, beginning with the September number.

Prof. Wiedemann justifies the association of physics with mathematics in the secondary schools, as is done in Germany, instead of the French practice of combining physics and chemistry, or physics with other sciences. He would, however, have intending teachers give some attention to chemical physics and become familiar with precipitation, filtration, crystallization, etc., and with the preparation of oxygen, hydrogen, carbon dioxide, etc. In mathematics he would have the candidate become familiar with analytical geometry; the calcultus, especially in its applications to physics; analytical mechanics; differential equations; and the theory of functions. Especially he would have him know elementary mathematics thoroughly and fundamentally, including the beginnings of the non-euclidean geometry.

He also justifies at.considerable length the elementary course in descriptive physics given to intending teachers, along with those looking forward to other professions, at the beginning of their university course. It is true that students coming from the oberrealschulen and realgymnasien can truly say, "We have heard all that before." Well, if they choose let them cut the lectures and have a good time; but those who attend will find that they have added much to their knowledge and understanding of the subject. They will hear to know and not, as previously, to be prepared for examination. They will get a more connected view of the subject, unobstructed by a multitude of applications. Above all they will form physical concepts directly from the physical world without the intervention of mathematical symbols and formulæ. So their knowledge will be real and not merely formal, as is 
likely to be the case if they go forward at once to theoretical physics. Students who are satisfied with purely formal definitions and who lean constantly upon the mathematical expression of physical ideas will, when they come to teach, be satisfied that their pupils have the same hollow semblance of knowledge. There is not time in the schools, often not the opportunity or the incentive to ponder the great things of physics, to let them sink into the mind and be really penetrated with them; so that the impression that physical subjects make is relatively weak and soon forgotten, as every university man knows. The schools all greatly misjudge as to the amount of abiding, well-digested, and utilizable knowledge which their students carry away with them. Especially is this true of the simplest concepts, which, just because they are so simple, are also so difficult.

Following this semester of descriptive and demonstrative physics two semesters of lectures are given upon theoretical physics, in which the chief stress is placed rather upon the physical content than upon the mathematical relations. This should give the students some ability to read original researches, where the mathematical demands are not too great, and some preparation for an "Arbeit" of their own. Lectures are also given upon particular departments of theoretical physics; upon the history of physics; and upon recent developments in the more important branches of the subject. Some practice is had in soldering, glass blowing, etc., and in preparing material for demonstration; though the writer does not think it worth while for the students to make complete pieces of complicated apparatus. The practical work is more exacting than that given to other students. Special attention is given to the experiments of the secondary schools: as-index of refraction, accurate weighing, etc. Great stress is placed upon the density of gases, for its manipulative value; but the densities of solids and liquids by different methods, specific heats, and a number of other problems, are worked hastily and with no very high degree of accuracy, so as to give time for some more advanced measurements:-as, the dielectric constants, polarization angles, heat of neutralization, elevation of boiling point, heat of combustion, etc.

In Bavaria the examination for intending teachers is divided into two parts: one after the fourth and one after the eighth semester. For the second part a scientific arbeit is demanded. Concerning the value of this arbeit to a teacher there has been 
much discussion, but the writer-thinks it equal in value to a dissertation in mathematics and justified by the fact that skill in using apparatus is always useful to a teacher.

Upon suggestion of the government officials they have hit upon the following scheme:

Themes, mathematical and physical, such as will come up for discussion in the schools, are distributed among the candidates. Those who specialize physics may get mathematical themes, and conversely. The candidate then has to treat the subject in a manner corresponding to the underlying knowledge and the power of comprehension of pupils and with apparatus such as he would use in early experimental work. Some one or other of the candidates will be able to prepare such apparatus, or it may be kept in stock. The point of these expositions does not lie in the correction of much formal awkwardness in presenting the experiment and analyzing it upon the blackboard, but in abundant instances of want of clearness-indeed of gross errors in comprehension-which come to light and may be corrected. They find the criticism of their fellow students useful, while the one who conducts the exercise gets a view of how much physical knowicdge, which he had taken for granted, is really a sealed book to many young people.

\section{A Communication.}

Edtor School Sctence and Mathematics:

In Milne's Plane and Solid Geometry, Book II, Proposition I, Cor. (Section 193), I see this statement: "In the same circle, or in equal

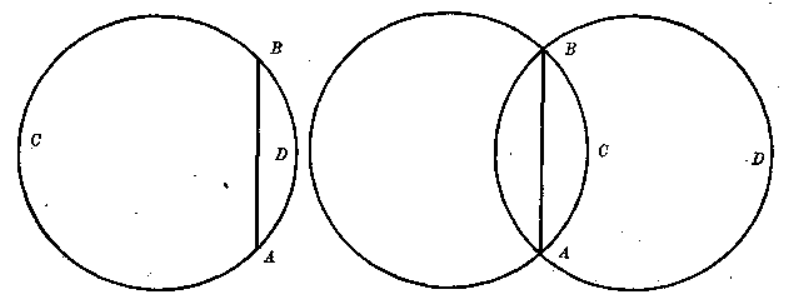

circles, arcs whose extremities can be made to coincide are equal." Is this true? In the following figures do not ares $\mathrm{ACB}$ and $\mathrm{ADB}$ meet the requirements of the hypothesis? Yet they are evidently unequal.

Yours truly,

O. L. Plunkett. 